\title{
LOS PICHICIEGOS: EL PODER SOBRE LA VIDA EN MANOS DE LA LITERATURA
}

\author{
LOS PICHICIEGOS: O PODER SOBRE A VIDA NAS MÃOS DA LITERATURA
}

\author{
María José Schamun ${ }^{1}$
}

\begin{abstract}
RESUMEN: El presente trabajo realiza una lectura de Los Pichiciegos de Rodolfo Fogwill desde la perspectiva de la biopolítica y la tensión por el poder sobre la verdad de los discursos sociales. En esta coyuntura, la literatura permite la vida de los cuerpos que han sido invisibilizados por el discurso "desmalvinizante" de los medios de comunicación, desde los cuales la guerra se presenta como un enfrentamiento entre la democracia y la dictadura. En este cruce, se genera, en cierta medida, una identificación entre los desaparecidos y los combatientes de Malvinas, al categorizarlos como víctimas del Gobierno de Facto. La literatura reclama el privilegio de pensar y reflexionar sobre los hechos, dotándolos de un sentido tan pleno que la ficción literaria se vuelve más necesaria y verosímil que el discurso periodístico. Durante el conflicto, el periodismo crea bandos y delimita territorios, inscribe cuerpos en lógicas que tienen diferentes grados de asidero en la realidad; después del conflicto, elimina los cuerpos y crea héroes intangibles. La literatura, en cambio, interviene en el imaginario colectivo y reclama un sentido para esos cuerpos presentes que el discurso mediático invisibiliza. La literatura articula las fases del proceso permitiendo reflexionar y sienta las bases de la memoria.
\end{abstract}

Palabras clave: Pichiciegos; Malvinas; biopolítica; literatura; periodismo; memoria.

RESUMO: O presente trabalho faz uma leitura de Los Pichiciegos de Rodolfo Fogwill a partir da perspectiva da biopolítica e da tensão pelo poder sobre a verdade dos discursos sociais. Nesse momento, a literatura permite a vida dos corpos que foram tornados invisíveis pelo discurso "desmalvinizante" da mídia, a partir do qual a guerra é apresentada como um confronto entre democracia e ditadura. Nesse cruzamento, em certa medida, é gerada uma identificação entre os desaparecidos e os combatentes das Malvinas, categorizando-os como vítimas do governo de fato. A literatura reivindica o privilégio de pensar e refletir sobre os fatos, dotando-os de um significado tão completo que a ficção literária se torna mais necessária e plausível que o discurso jornalístico. Durante o conflito, o jornalismo cria lados e delimita territórios, inscrevendo corpos em lógicas que têm diferentes graus de aderência à realidade; após o conflito, elimine corpos e crie heróis intangíveis. A literatura, por outro lado, intervém no imaginário coletivo e reivindica um significado para os corpos presentes que o discurso da mídia torna invisível. A literatura articula as fases do processo, permitindo refletir e lançar os fundamentos da memória.

Palavras-chave: Pichiciegos; Malvinas; biopolítica; literatura; Jornalismo; memória.

\footnotetext{
1 Licenciada y profesora de nivel medio y superior en Letras, orientación en Literatura Argentina y Latinoamericana, UBA. Adscripta del Instituto de Literatura Hispanoamericana, UBA.
} 


\section{Introducción}

$\mathrm{Si}$ "No hay lugar para oponer lo que ha inventado un cerebro humano a lo que realmente existió. Porque el mundo cuya realidad diariamente experimentamos no es él mismo otra cosa que el redescubrimiento del mundo natural por el mundo que el cerebro humano ha producido" (RANCIÈRE, 2019, p. 110) podemos comprender la relevancia de una novela como Los Pichiciegos para una sociedad que ha construido su actual democracia sobre la negación de la legitimidad de la guerra de Malvinas.

La novela se desarrolla “...como relación de espacios. Pero también cada lugar es múltiples cosas a la vez y la ficción se construye como una relación entre múltiples formas de realidad" (RANCIÈRE, 2019, p. 116) que permiten poner al descubierto el sinsentido de la guerra y su lógica (ya sea la discursiva o la del combate físico), así como su parodia desde el interior mismo del conflicto. La primera parte de la novela transcurre en las Islas mientras que la segunda se desarrolla en la ciudad de Buenos Aires, y tanto en una como en otra, las relaciones de poder son cruciales para el desarrollo de la trama que terminará por rendir el poder de la vida al discurso que se presenta como la memoria de la experiencia bélica. La novela brinda a los textos testimoniales la capacidad de mantener con vida, como individuos sociales, a quienes regresaron del campo de batalla. Sin embargo, "el problema no es relacionar todo con todo, sino tejer [...] un territorio de coexistencia” (RANCIÈRE, 2019, p. 116) en el cual quienes participaron físicamente de la guerra en las Islas puedan encontrar un lugar de pertenencia entre quienes se quedaron en el continente en ese presente democrático que se abre después de la guerra y que se empeña en negarla por medio de estrategias de invisibilización de sus participantes. "Las dificultades para circular que encontraron los relatos de un hecho de guerra en el marco de la naciente democracia, que buscaba asentar sus bases sobre un relato pacificador y marcar un corte tajante con la violencia del período precedente" (SEGADE, 2015, p. 140) hicieron casi imposible que la sociedad pudiera incorporar al flujo de la vida cotidiana, a quienes habían formado parte del enfrentamiento. "Es a partir de este olvido que debe pensarse el trabajo de la ficción. No se trata simplemente de conservar la memoria. Se trata de construir una memoria que inserte en una topografía justa..." (RANCIÈRE, 2019, p. 111) a la figura del soldado de Malvinas, que le otorgue una identidad a esos cuerpos que, habiendo regresado del combate, habitan entre quienes se niegan a reconocerles su pasado y, por tanto, su identidad.

Ese olvido del que habla Rancière, en el caso de la Guerra de Malvinas, adquiere una materialidad que pone en peligro la subsistencia de los excombatientes y es por eso que esa invisibilidad que el discurso ejerce sobre la figura del relato bélico, se vuelve invisibilidad de un elemento de la sociedad que queda apartado del conjunto social y cuya existencia se está poniendo en peligro, no solo como elemento discursivo, sino también como vida humana en sí mismo.

Por lo tanto, las relaciones de poder que la novela entreteje tienen una continuidad en el tiempo en el mundo real (valga decir, en de los cuerpos de carne y hueso). En la primera parte del relato literario, se pondrán en juego las vidas de los combatientes y su subsistencia dependerá de su capacidad de comprender y sustraerse del discurso bélico, de ponerse al margen del mismo y "tejer" un discurso tangencial que permita un espacio apartado en el cual sobrevivir a una guerra que ya perciben como perdida. Es necesario, en este punto, comprender que la figura del combatiente está compuesta de dos elementos humanos diferentes: el colimba y el soldado. El primero no participa de forma voluntaria en el acto bélico y no posee formación 
ni convicción respecto del uso de la violencia, de sus mecanismos o estrategias; mientras que el segundo, por su parte, ha recibido formación y ha tomado una elección consciente de ser partícipe de la contienda. Esta diferencia, supone actitudes diferentes respecto del discurso social y político e torno a la guerra, implica la posibilidad de formar parte del enfrentamiento sin creer en su capacidad de transformación de la realidad.

En línea con estas posibilidades, toda

[...] guerra se plantea explícitamente como un objetivo político $-\mathrm{y}$, en el fondo, no simplemente como un objetivo político para obtener una serie de medios, sino como una especie de fase última y decisiva de todos los procesos políticos-, la política debe conducir a la guerra, y ésta debe ser la fase final y decisiva que coronará el conjunto (FOUCAULT, 2001, p. 234)

pero al regresar, quienes han contribuido a esa coronación, no serán aceptados como miembros del conjunto. Es en ese momento entonces, en el que comienza una guerra de discursos por lograr la legitimidad, por conquistar el estatuto de verdad y, por lo tanto, la posibilidad de insertar como actores válidos a los personajes que propone. Es en este momento en el que la palabra combatiente cobra pleno sentido porque, a diferencia de soldado, permite la inclusión de quienes fueron lanzados a esa situación sin haber tenido la posibilidad de elegirla. Entonces, la memoria no es solamente un recuento de los hechos, sino una herramienta transformadora de la realidad presente.

\section{La lógica de la guerra}

Todo relato que tenga como uno de sus elementos el enfrentamiento bélico tendrá, sí o sí, que tratar con el discurso del poder porque es allí, en el discurso, donde se organizan bandos y se da sentido a la realidad que se está viviendo en el campo de batalla. Las lealtades de los combatientes se definen a partir de la palabra y el territorio: un mapa y un documento de identidad, haber nacido en un lugar, "ser escrito" dentro de una nación.

- Quería saber... ¿Si vos sos uruguayo, por qué carajo estás acá?

- Porque me escribieron argentino. ¡Soy argentino! (FOGWILL, 2010, p. 12)

Sin embargo, si bien en la novela de Fogwill la guerra es uno de los elementos centrales, la organización del texto no sigue la lógica bélica. La trama no trabaja de manera simple en la oposición entre vencedores y vencidos, ni entre un nosotros y el enemigo; sino que se desarrolla, en palabras de Schvartzman, desde "[...] la corrosión de los límites entre los bandos, de la negativa cínica a hablar en serio de los valores invocados." (SCHVARTZMAN, 1996, p. 139). Es por este motivo, que la novela despliega relaciones de poder que se apartan de la jerarquía militar y se desentienden de la lógica dicotómica "argentinos-ingleses": los oficiales nacionales y el ejécito extranjero son reconocidos como aquellos con el poder de dejar y de hacer morir respectivamente y, por este motivo, son percibidos por muchos de los soldados, como el oponente. Mientras tanto, dentro de la comunidad de desertores se organiza una lógica jerárquica interna que responde a lo que Foucault llama el "derecho de soberanía" y que "es, entonces, el de hacer morir o dejar vivir" (FOUCAULT, 2001, p. 218). Este poder lo ejercen los personajes que se hacen llamar "reyes": 
-Los Reyes mandan y nadie más manda y el que quiera mandar se va y no es más pichi y va a ver qué le pasa.

Así explicaban cada vez que había un problema. ¿Quién se iba a ir? Si se fuera un pichi y pasase al lado argentino contaría el lugar donde vivían los pichis y los cazaban a todos, pero a él también lo metían preso, por haber sido pichi, o lo mandaban al frío, o a ahogarse en las trincheras. Nadie iba a querer dejar de ser pichi. (FOGWILL, 2010, p. 46)

De una u otra forma, los personajes envueltos en la trama responden a dos lógicas distintas: la lógica de grupo, de bando; y la lógica del individuo, del combatiente. En tanto bando, su función es la de vencer al bando opuesto a toda costa; en tanto individuos, su función es causar la mayor cantidad de muertes al enemigo, reducir sus condiciones de supervivencia. Toda guerra tiene, por lo menos, dos bandos que se enfrentan en torno a la posesión de un bien o territorio. En Los Pichiciegos, la guerra tiene argentinos, ingleses y pichis.

Si bien siempre existe en la guerra un peligro dentro de las propias filas, los traidores (espías o desertores, ambos son interpretados de la misma forma), en la novela de Fogwill, esta perspectiva está invertida y, por lo tanto, los traidores no son los desertores (los pichis) sino los oficiales que, indiferentes a la suerte de sus soldados, los dejan morir a la intemperie, de frío (valga decir, de desprotección de un Estado que los abandonó a su suerte en nombre de una tierra que ninguno de ellos conocía y en función de una identidad nacional que se muestra tan ficticia $^{2}$ como la posibilidad de ganar la guerra). Entonces, si tenemos en cuenta que cualquiera de nosotros para poder funcionar debe insertar las acciones dentro de un marco que les dé sentido, "Este marco interpretativo funciona diferenciando tácitamente entre las poblaciones de las que depende mi vida y mi existencia y las que representan una amenaza directa a mi vida y mi existencia. Cuando una población parece constituir una amenaza directa a mi vida, sus integrantes no aparecen como 'vidas' sino como una amenaza a la vida." (BUTLER, 2010, p. 69) Por lo tanto, desde este punto de vista, las relaciones de poder se ven desplazadas y la lógica del enfrentamiento se vuelve lo que Schvartzman (1996, p. 136) llama "una picaresca de la guerra" en la que ya "no se trata de vencer a ningún enemigo" (FOGWILL, 2010, p. 143) sino de poner en juego estrategias para sustraerse a su poder de hacer morir, porque la superioridad de los ingleses no se pone en tela de juicio como tampoco su desinterés por las vidas de los soldados argentinos y, en este punto, los oficiales ingleses y los argentinos se igualan en tanto amenaza a la vida y, al mismo tiempo, los ingleses son los que poseen los medios de subsistencia por lo que, a pesar de ser el enemigo declarado, en el marco interpretativo antes especificado, son también (y en parte) aliados.

[...] [Los oficiales ingleses] Con ellos [Los oficiales argentinos] son como iguales, se tratan como iguales, toman el té juntos. Son capaces de cambiarte por algo y hacerte fusilar. [...] Les habían dado un fajo de copias de las fotos de los oficiales rendidos tomando té con los capitanes de los barcos de la flota británica. [...] Los ingleses habían pedido que los pichis las repartieran entre los de Intendencia, para apurar la rendición. -¡Tirémoslas! iQue no se rindan! Que se maten entre ellos y que se vayan a la puta que los parió todos. ¡Las tiramos y les decimos que las repartimos igual...! (FOGWILL, 2010, p. 47)

\footnotetext{
${ }^{2}$ Las diferencias en la educación de los pichcis que no saben lo básico sobre historia o geografía hace cuestionable que se pueda decir que todos pertenecen a una misma comunidad nacional.
} 
En el fragmento anterior, se ve perfectamente cómo los pichis quedan en los márgenes de la lógica del enfrentamiento y, por lo tanto, su vida en el campo de batalla no se ve amenazada por los peligros de la guerra sino de la intemperie. Ese campo que no llega a ser campo de ninguna batalla se vuelve el escenario de una farsa de la guerra al "...ubicar la acción en el margen de la guerra e instalar, simultáneamente, al desertor como personaje principal; es decir, elegir a quien abandona no solo la guerra sino también su lógica y su relato" (SEGADE, 2015, p. 157). Desde ese margen, las relaciones de poder se ven tergiversadas: no hay dos bandos peleando por el dominio sobre algo (tierra o vida) sino un bando que ostenta el poder tanto sobre la vida como sobre la muerte y otro que se limita a resistir el frío y el hambre.

Los ingleses demuestran una y otra vez que mantienen el control de lo que sucede: compran la información a soldados evadidos, bombardean y diezman las reservas argentinas, pero todas sus acciones se desarrollan dentro del marco de las reglas de la guerra. Son estas reglas las que les permiten a los pichis negociar y mantenerse con vida porque saben que, al ingresar en territorio inglés, por ejemplo, no van a fusilarlos sino a apresarlos, porque saben que, ante todo, los ingleses quieren la rendición del enemigo. En esta lógica, lo que queda en evidencia es que el enfrentamiento es una farsa: Inglaterra tiene la posesión efectiva de un recurso que Argentina disputa poniendo en peligro las vidas de sus ciudadanos en nombre de una Nación cuya unidad e identidad se ve cuestionada al comprobar que sus integrantes sólo tienen en común el desamparo del frío y el hambre. A este respecto, la frase de Quiquito "Esto es de ellos" (FOGWILL, 2010, p. 47) cobra un sentido pleno al comprender que los ingleses tienen el poder soberano sobre las vidas de quienes están en las islas: pueden hacerlos morir o dejarlos vivir, algo que los argentinos no logran siquiera con sus propios desertores.

Lo anterior se efectúa en el plano amplio de lo que se plantea como un enfrentamiento bélico, pero al mirar hacia el interior de la comunidad de pichis, lo que se verifica es una lógica bastante distinta. Si bien su emergencia como comunidad se debe a la existencia de la guerra (como una imitación burda de la comunidad nacional cuya unidad se logra frente a la imagen del enemigo), el motor de sus acciones es la propia supervivencia y no la muerte del oponente. Dentro de la pichicera, la vida de cada uno tiene un valor y es el de hacer vivir al resto: cada uno que llegue debe aportar conocimiento o víveres. En el momento en que dejan de ser útiles porque sus conocimientos o actividades no suman a la supervivencia del resto, su vida cambia de signo y se transforma en una amenaza de la que hay que deshacerse. En esta instancia, el poder de decisión lo tienen quienes crearon la comunidad y son ellos, los Reyes, quienes (como los ingleses en el campo) tienen el poder soberano de hacer morir o dejar vivir. Sin embargo, a diferencia de lo que sucede con los ingleses, los reyes necesitan de otros para mantenerse con vida por lo que esa relación de poder tiene una contracara: necesitan de otros para obtener comida y abrigo. De este modo, en la primera parte, la novela pone en juego dos niveles en cuanto a las relaciones de poder: los ingleses son los soberanos de ese campo helado en el cual pueden matar o dejar con vida los soldados enemigos siempre con la intención de amedrentar, no de aniquilarlos; y los Reyes Magos dentro de la pichicera pueden matar o dejar que sigan viviendo quienes demuestran su utilidad para la supervivencia. Este desplazamiento de la lógica de la guerra de dos bandos a dos bandos y un margen hace que se generen lógicas de acción distintas, en espacios distintos, pero en un mismo tiempo. Los soldados argentinos que se mantienen bajo las órdenes de los oficiales morirán por el ataque del enemigo y de frío dentro de los márgenes de lo que la lógica de la guerra permite plantear. Los desertores sobrevivirán sustrayéndose a la lógica de la guerra y lidiando con las vicisitudes de la naturaleza y la supervivencia en un medio que les es ajeno. De este modo, para los pichis, la forma de 
sobrevivir no es ganar la guerra (lo que se considera imposible), sino escapar al gobierno de los oficiales y someterse al de los Reyes, desertar de la lógica bélica.

\section{El poder del discurso}

A lo largo de la segunda parte de la novela, el poder sobre la vida se vuelve metafórico: ya no se trata de la supervivencia física sino de la visibilidad y, por lo tanto, de la existencia como tales, de los combatientes que vuelven de ese campo de batalla para dar fe de que el enfrentamiento fue una farsa. Si la guerra había sido, como el discurso oficial perjuraba, una gran batalla en la que nuestros patriotas habían luchado y entregado la vida como verdaderos héroes defendiendo la soberanía de la Nación, no podía admitirse la existencia de sobrevivientes. A fin de sostener el discurso épico, se busca crear una figura del vencedor que es implacable y, en esa lógica, la devolución de los soldados rendidos resulta incoherente porque demuestra que de haberse rendido antes, habrían salvado la vida y, por lo tanto, transforma la muerte de los que sí habían caído en insignificante e innecesaria. Todo este contexto que es en general similar en toda guerra, en el caso de la Guerra de Malvinas se ve acentuado en sinsentido al quedar vinculado el conflicto a un gobierno al que no se le reconoce legitimidad y, por lo tanto, tampoco se ve como legítima la guerra a que lideró. Por este motivo, el desconocimiento de quienes vuelven con vida de las islas se vuelve necesario para el discurso oficial que, en estas circunstancias, sólo tiene dos opciones: mostrar a los soldados como parte del cuerpo militar y, por lo tanto, vincularlos a los represores; o desmilitarizarlos y transformarlos en "los chicos", víctimas inocentes de los militares que los hicieron morir en la guerra. De este modo, incluso si habían sobrevivido, habían muerto para la sociedad.

Si la realidad es el relato que articulamos sobre aquello que nos rodea, todo lo que existe es discurso y lo que éste no dice, no tiene entidad. Durante la segunda parte de la novela, Quiquito se niega a concederle a su interlocutor el conocimiento sobre lo que ha pasado: para él hay algo más que el discurso y ese algo es la experiencia. Le resulta imposible creer que quienes no hayan vivido en ese frío o sentido el estruendo de las bombas retumbándole en todo el cuerpo puedan entender de verdad lo que es el frío o el miedo. De pronto, Quiquito pone en tela de juicio la capacidad de las palabras de dar cuenta de la experiencia y, sin embargo, no deja de hablar, el campo de batalla no lo ha dejado mudo. Esta capacidad se debe en parte a que los combatientes de Malvinas tienen un marco de referencia en el cual insertar las experiencias que han vivido aun cuando excedan o frustren las expectativas y, desde un comienzo, la realidad de las islas escapa a las expectativas. "Que no era así, le pareció" (FOGWILL, 2010, p. 9) Todas las ideas sobre la guerra que tienen los personajes, provienen de las películas: la nieve, el sonido de las bombas, la forma de sobrevivir a la guerra o la posibilidad de ganarla, son parte de discursos ficcionales que se enfrentan al sinsentido de ese "método inglés" que se aleja de la idea de la guerra que la ficción ha instalado. "Ése es el método que tienen ellos. ¿O te creés que la guerra es tirar y tirar? La guerra es otra cosa: ¡es método! Y ellos tenían el método -dijo.” (FOGWILL, 2010, p. 91)

En esa idea de que la guerra no es "tirar y tirar" se pone en evidencia que el poder sobre la vida del otro está ejercido desde el discurso, desde la generación del miedo y el convencimiento de la derrota. La rendición no se logra masacrando los cuerpos sino ostentando el poder de hacerlo, demostrando que el soberano es quién detenta la capacidad de matar, incluso (o, sobre todo) cuando permite vivir. Entonces comienza la guerra discursiva: los soldados regresan de las islas y se encuentran con una versión en la cual “...se había perdido una 
batalla, pero que la guerra era más que eso y que ahora había que ganarla obedeciendo y respetando al superior, porque ése era un ejército de San Martín.” (FOGWILL, 2010, p. 89). Pero acto seguido, la imagen del gran general se ve aplastada por la realidad de las islas "Una vez un teniente habló en la isla de que los oficiales tendrían que hacer como San Martín y un capitán le dijo que a San Martín, en las Malvinas, se le hubiera resfriado el caballo.” (FOGWILL, 2010, p. 89) En esa burla se deja ver el desfasaje entre la imagen que los medios habían construido sobre la guerra y la guerra misma.

Pero al segundo coronel habría que haberlo grabado para la televisión. Hablaba a todos, había cerca de mil: había parientes, novias y políticos. Y todos los vueltos, ahí, oyéndolo, esperando que les dieran permiso para ir a la verja a buscar cigarrillos y choripanes [...] Y el tipo hablaba. Que éramos como el ejército de San Martín. "Heroicos", repetía. (FOGWILL, 2010, p. 89)

Es este el momento en el cual se verifica el cambio en la lógica de la relación de los discursos. Si en la primera parte la nieve no era así, amarilla y pegajosa como él podía sentirla con su propio cuerpo, sino blanca y suave como en la pantalla del televisor; ahora la grandilocuencia y la exageración son los que quedan del lado del discurso mediático y la verdad queda definitivamente del lado de la experiencia. Una experiencia que se resiste a ser transmitida, a ser aprehendida de manera cabal, pero que puede expresarse, que puede ponerse en palabras y articularse, aunque más no sea, como oposición a la ficción del discurso oficial.

La tensión entre el discurso periodístico y el literario, entre la voz y la escritura, entre la experiencia y su relato juega constantemente con el atributo de verdad. La novela pone en juego la forma del testimonio y entra en una zona gris (como los personajes en las islas) al poner su discurso en tela de juicio: es un texto literario, pero es un testimonio del sinsentido. La lógica temporal del relato se ve alterada cuando el lector entiende que lo que leyó en la primera parte está siendo grabado en la segunda: la primera mitad de la novela es el producto de algo que, en la segunda parte, aún no ha sucedido. Por lo tanto, la primera mitad es un texto "en limpio" mientras que la segunda sería un borrador. En este pasaje se genera un tono de urgencia en lo que está siendo contado, como si el ritmo en el que se está pasando en limpio lo que relata el sobreviviente no fuera suficiente. Esta urgencia que más típica del género periodístico que de la literatura se relaciona con el tiempo muerto de los acontecimientos reales de los cuales el periodismo busca dar noticia, frente al relato ficcional que puede eliminar esos lapsos al condensar la trama. Por lo tanto, la urgencia del relato periodístico se encuentra en el centro de su naturaleza: lo periódico se renueva día a día, y cada día debe ser algo diferente. Esta falta de distancia respecto de los hechos relatados, no permite un pensamiento por fuera de la coyuntura en la que los sucesos acontecen y, por eso, el relato de los hechos, evade el sentido de los mismos. Sin embargo, los aspectos que se transmiten y la forma que adquiere esa transmisión crean la realidad presente e inmediata en la cual la sociedad está viviendo: el discurso es el que dota de sentido a la realidad en vez de encontrarlo en las $\operatorname{cosas}^{3}$. A partir de esta diferencia fundamental, la novela está poniendo en manos del discurso periodístico la posibilidad de visibilizar a los sobrevivientes mientras guarda para sí la capacidad de mirar los

\footnotetext{
3 “[...] inmediatamente después de la guerra de Malvinas, en 1982, el Informe Rattenbach -comisión investigadora creada durante la dictadura para analizar lo ocurrido- criticó a la conducción militar por [...] que afirma que los generales mediáticos pudieron imponer a los generales reales la gestión de la guerra.” Ruiz, Fernando J. Guerras mediáticas: Las grandes batallas periodísticas desde la Revolución de Mayo hasta la actualidad. Buenos Aires: Sudamericana, 2014; p. 10.
} 
hechos críticamente desde la lógica de la circunstancia más que desde la moral y re-crearlos dotándolos de un nuevo sentido.

Desde la perspectiva del discurso, entonces, se teje una trama muy completa respecto del poder sobre la vida: si bien en la segunda parte de la novela es un periodista quien tiene el poder de hacer visible la historia y, por lo tanto, de "hacer vivir" la experiencia para quienes no la conocen; es la literatura la que permite ver esta función del periodismo en la sociedad. Por lo tanto, en un sistema de cajas chinas, el poder último lo tiene la literatura que aun sin dejar de lado el estatuto de ficción, es capaz de crear un sentido que incluye esas historias que los periódicos y noticieros no incluyen porque no encuentran una razón de ser en el esquema de sentido que han organizado para ese presente. Rancière menciona un fenómeno que se da luego de la Segunda Guerra Mundial, que explica la negación del discurso mediático a dar cuenta de la vida de los sobrevivientes y sería el retorno a "...'la vida social': la vida de hombres apresurados 'por olvidar lo que no quieren saber, por retirar la mirada de lo que tienen delante de ellos' (SEBALD apud RANCIÈRE, 2019, p. 112) para construir, sobre las ruinas enterradas de una voluntad de destrucción, la inocente prosperidad..." (RANCIÈRE, 2019, p. 111). En el caso de la guerra de Malvinas, no se trata, en este caso del retorno de los soldados a la vida social, soldados que buscan dejar atrás la guerra, sino de una sociedad que no logra incorporar la guerra a su presente democrático, que asocia el enfrentamiento bélico a la dictadura y, por lo tanto, a los combatientes de Malvinas con los militares represores. "[...] las dificultades para circular que encontraron los relatos de un hecho de guerra en el marco de la naciente democracia, que buscaba asentar sus bases sobre un relato pacificador y marcar un corte tajante con la violencia del período precedente" (SEGADE, 2015, p. 140) determinaron la invisibilidad de los sobrevivientes de la Guerra de Malvinas y pusieron en peligro su existencia. Mientras los soldados buscaban comprender y reformular la idea de su propia identidad buscando su lugar en la sociedad, la sociedad buscaba eliminar la figura del soldado de la vida democrática.

\section{Conclusiones}

Si "El grabador abrió la posibilidad de copiar la voz y de copiar la historia de aquellos que están fuera del mundo letrado, y en ese sentido produjo una transformación en la escritura y generó un campo nuevo como es, básicamente, el de la no ficción” (PIGLIA, 2016, p. 41) se comprende el poder que tiene ese elemento en la segunda parte de la novela al permitir el entrecruzamiento de discursos y la incorporación de la voz del otro. Ese otro se incorpora a la realidad desde la literatura, desde la ficción, desde la cual se abre camino hacia la realidad a partir de su devenir personaje. El poder de la literatura es devolver la realidad a aquellos cuerpos que, salpicados dentro del cuerpo social, no logran integrarse a fuerza de ser silencio en los discursos mediáticos oficiales. Lo que se pone en juego entonces es el estatuto de verdad que permitirá a una versión de los hechos ganar la legitimidad y hacer vivir a quienes, hasta el momento, el discurso "desmalvinizante" ${ }^{4}$ busca hacer morir para que la democracia no se vea amenazada. Sin embargo, la novela de Fogwill no reclama "la verdad" sino que pone en evidencia las falencias de los discursos que sí lo hacen.

$\mathrm{Si}$ “...la vanguardia sería un tipo particular de socialización de un problema interno a la literatura relacionado con la lucha entre poéticas, el enfrentamiento entre los distintos sistemas

\footnotetext{
${ }^{4}$ El concepto de "desmalvinización” lo acuñó el sociólogo francés Alain Rouquié en una entrevista que le hiciera Osvaldo Soriano para la revista Humor en marzo de 1983. (SEGADE, 2016, p.141)
} 
de lectura y de valorización de los textos" (PIGLIA, 2014, p. 43) podemos pensar en la novela de Fogwill como una vanguardia social más que literaria. Los Pichiciegos se presenta como un relato de la guerra que busca ganar el territorio de la representación de ese conflicto para imponer su lógica y desarticular las dicotomías establecidas desde los medios masivos de comunicación. La novela permite entrever una realidad nueva y abre la posibilidad de un relato social que de lugar a la coexistencia de elementos que el discurso oficial plantea como separados en el tiempo, lejanos en el espacio e ideológicamente antagónicos.

\section{Bibliografía}

BUTLER, J. Marcos de guerra. Buenos Aires: Paidós, 2010.

FOGWILL, R. Los Pichiciegos. Visiones de una guerra subterránea. Buenos Aires: Biblioteca pública, 2010.

FOUCAUlT, M. Defender la sociedad. Buenos Aires: Fondo de Cultura Económica, 2001.

PIGLIA, R. Las tres vanguardias. Buenos Aires: Eterna Cadencia, 2016.

RANCIÈRE, J. Los bordes de la ficción. Buenos Aires: Edhasa, 2019.

RUIZ, F. J. Guerras mediáticas: Las grandes batallas periodísticas desde la Revolución de Mayo hasta la actualidad. Buenos Aires: Sudamericana, 2014

SCHVARTZMAN, J. Microcrítica. Buenos Aires: Biblos, 1996.

SEGADE, L. Lejos de la guerra. Relatos de Malvinas en los primeros años de la democracia. Páginas, Rosario, año 7, número 13, pp. 137-160, 2015. Disponible en: <http://paginas.rosarioconicet.gob.ar/ojs/index.php/RevPaginas>

Recebido em: 09/04/2020

Aceito em: 23/06/2020 